17.1

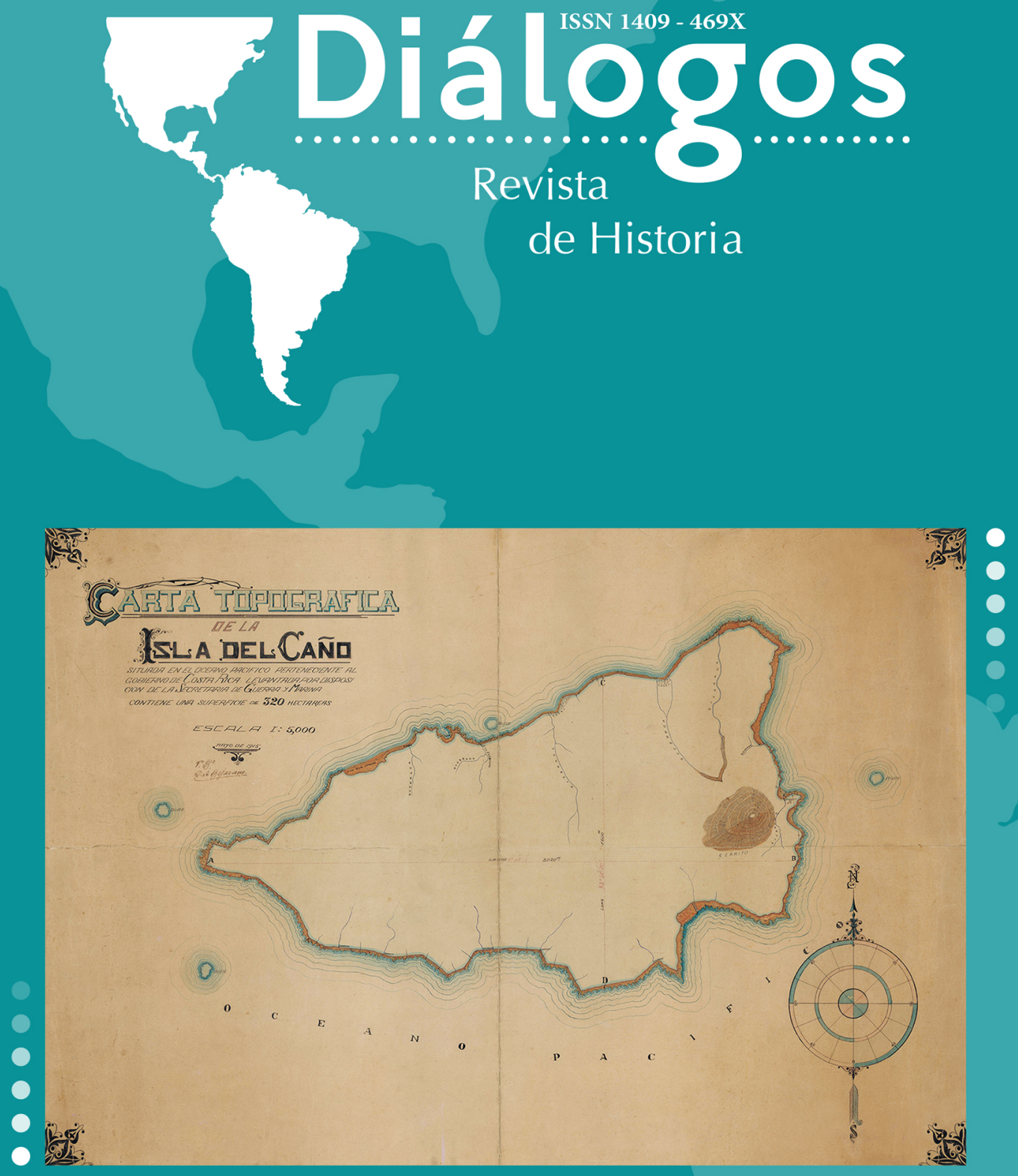

Escuela de Historia. Universidad de Costa Rica

Enero-junio 2016

url: http://revistas.ucr.ac.cr/index.php/dialogos/index 


\title{
LA EVOLUCIÓN DE LA AEROLÍNEA AVIANCA EN FUNCIÓN DE LA EVOLUCIÓN DE SU CONTEXTO
}

\author{
Javier Humberto Ospina Holguín
}

\begin{abstract}
Resumen
El propósito de este artículo es exponer la evolución de la aerolínea colombiana Avianca como una función de la evolución de su contexto. Con base en una revisión bibliográfica y hemerográfica, se realiza un análisis de la trayectoria de la compañía expresada en función de la dinámica de su entorno histórico, análisis que se inspira en consideraciones constructivistas y de las ciencias de la complejidad. Aspectos como la I y II guerras mundiales, los desarrollos tecnológicos, el imperialismo estadounidense y la política y la economía nacional labran de manera fundamental la trayectoria de la empresa entre 1919 y 1940; mientras que los desarrollos tecnológicos, la naturaleza monopolista del sector, las luchas entre los grandes grupos empresariales nacionales, la adopción de la apertura económica, las leyes y las relaciones laborales, el narcotráfico y el terrorismo internacional junto con la crisis del petróleo lo hacen en el periodo 1940-2014. Se concluye que Avianca es una empresa "procíclica" marcada especialmente por la evolución del factor socioeconómico de su entorno, pero que otros factores influyen de manera importante en su evolución.
\end{abstract}

Palabras claves: aviación civil, Colombia, empresa privada, historia latinoamericana.

\section{THE EVOLUTION OF AVIANCA AIRLINES IN TERMS OF THE EVOLUTION OF ITS CONTEXT}

\begin{abstract}
The purpose of this article is to present the evolution of the Colombian airline Avianca as a function of the evolution of its context. Based on a selected bibliography and press excerpts, an analysis of the trajectory of the company expressed in terms of the dynamics of its historic setting is done, an analysis inspired by constructivist and sciences of complexity considerations. Aspects such as the First and Second World Wars, technological developments, US imperialism and the political and national economy fundamentally forge the trajectory of the company between 1919 and 1940; while technological developments, the monopolistic nature of the sector and the struggles between the major national business groups, the adoption of economic openness, labor relations and laws, drug trafficking and international terrorism and the oil crisis do so in the period 1940-2014. It is concluded that Avianca is a "pro-cyclical" company especially marked by the evolution of the socio-economic factor of its environment, but other factors significantly influence its evolution.
\end{abstract}

Keywords: civil aviation, Colombia, private enterprises, Latin American history.

Fecha de recepción: 15 de junio de 2015 • Fecha de aceptación: 9 de setiembre de 2015

- Javier Humberto Ospina Holguín - Facultad de Ciencias de la Administración.
- Universidad del Valle. Sede San Fernando. Cali, Colombia 


\section{INTRODUCCIÓN}

En este artículo se analiza la trayectoria histórica de una de las organizaciones más emblemáticas de Colombia: la aerolínea Avianca con casi 100 años de historia. Enmarcado en la perspectiva de la historia empresarial, en el artículo se postula que la historia de esta organización discurre en términos de una coevolución con su entorno. El análisis recurre en cierta medida a las recientes teorías de la complejidad: desde una perspectiva compleja, "los elementos dependen de características globales, y las características globales de los elementos" (Prigogine, 1997, p. 180) y la organización puede ser vista, adoptando la metonimia de la autopoiesis, como una entidad que, una vez establecida, es circular o autoreferente en el sentido de que sus acciones tienden a autoperpetuarla en reacción a los cambios en el entorno (Maturana y Varela, 1994, pp. 45-46, 51). En Avianca esta interacción entre lo local y lo global, donde Avianca afecta a su entorno y el entorno afecta a Avianca, y la autopreservación de Avianca a lo largo de un proceso que involucra por lo menos seis grupos económicos y cinco denominaciones diferentes evidencian la importancia de recurrir a la perspectiva compleja.

El artículo se inspira también en la perspectiva constructivista de las ciencias de la gestión. Le Moigne (1997) caracteriza a las modernas ciencias de la gestión de una incoherencia epistemológica:La incoherencia se refiere a que la validación científica de una teoría en ciencias de la gestión se basa en la reputación del investigador que la publica (reputación adquirida en otra disciplina) o en la reputación del método que se usa para elaborar la teoría (reputación lograda en otra disciplina). Esos criterios pueden ser tranquilizadores, pero epistemológicamente son incompatibles con los que proponen los epistemólogos positivistas normales (y que, por tanto, son socio-culturalmente aceptados). (p. 170).

Una alternativa epistemológica a esta situación la da el así llamado constructivismo que para Albert David se caracteriza esencialmente porque, de acuerdo con esta corriente, el hombre no accede a la sustancia de las cosas, sino a su propia experiencia de ellas; la finalidad o motivación de las situaciones humanas es relevante, se renuncia al dualismo sujeto-objeto (el objeto es solo una representación que se hace el sujeto), se renuncia a la lógica disyuntiva en aras de una lógica de la argumentación y la teoría más simple no necesariamente es la mejor, sino que pueden coexistir múltiples teorías “adecuadas” (Muñoz, 2011, pp. 96-98). Estos preceptos constructivistas iluminan todo nuestro análisis.

El análisis discurre en dos momentos: primero identificamos "los hechos" acaecidos y luego analizamos la evolución de la compañía en función del entorno, entorno que pone en contexto y explica parcialmente estos "hechos". Desde el constructivismo sabemos que no existen los hechos desnudos, como apuntan Bourdieu, Passeron y Chamboredon (1975): "No hay operación por más elemental y, en apariencia, automática que sea de tratamiento de la información que no implique una elección epistemológica e incluso una teoría del objeto" (p. 68). Los "hechos" 
son, así, solo una posible interpretación o representación de lo sucedido. A pesar de ello, nuestro análisis intenta ser lo más neutral posible, como correspondería a una investigación histórica empresarial (Avenier, 1989), aunque intenta también, en cierta manera, comprender el porqué profundo de ciertos sucesos, no solo en términos de causas eficientes, sino también en términos de causas finales - "con el fin de qué, en razón de qué ocurren las cosas o qué sentido tienen” (Muñoz, 2011, p. 57) - , por ejemplo, por qué el Grupo Santo Domingo se aferraba a Avianca cuando esta generaba pérdidas.

Para facilitar el análisis dividimos la historia de Avianca en dos partes: la primera comprende el periodo 1919-1940, y la segunda, el periodo 1940-2014. La sección 2 presenta la evolución de la compañía en función de la evolución de su contexto para cada una de las dos etapas. La sección 3 concluye.

\section{EVOLUCIÓN DE AVIANCA EN FUNCIÓN DE LA EVOLUCIÓN DE SU CONTEXTO}

\section{Historia de Avianca: parte I (1919-1940)}

\section{Los "hechos"}

Hacia 1910 diversos pilotos habían llegado del exterior para realizar vuelos de exhibición en distintas ciudades de Colombia, entre otras, Bogotá, Medellín y Barranquilla; no obstante, ninguno de estos vuelos se realizaron exitosamente (Aviación y Turismo, 2012). Tan solo en 1913, específicamente el 26 de enero, se llevó a cabo el primer vuelo de manera exitosa; el piloto fue John Smith, de quien poco se sabe (Aviación y Turismo, 2012). Ya en 1919, dos empresarios colombianos, Carlos Obregón y Ulpiano Valenzuela, habían adquirido un Curtiss Standar J-1 en Nueva York - que llegaría dos años más tarde a Colombia - con el propósito no solo de realizar nuevas demostraciones, sino también de fundar una aerolínea (Aviación y Turismo, 2012). En Nueva York, Obregón y Valenzuela conocieron al piloto William Knox Martin quien llegó en mayo de 1919 al país, trayendo su avión propio, el cual llegaría a Barranquilla en una caja en junio (Aviación y Turismo, 2012). En Barranquilla, Martin entró en relaciones en los clubes sociales con tres jóvenes empresarios: Antonio de Castro, Ernesto Cortissoz y Mario Santo Domingo - este último el futuro padre de Julio Mario Santo Domingo- (Aviación y Turismo, 2012). El 15 de junio de 1919, Martin hace su primer vuelo de prueba sobre Barranquilla, y un nuevo vuelo, el 18 de junio de 1919, marca el origen del servicio aéreo postal en Colombia: Mario Santo Domingo se atrevió a acompañar a Martin en este vuelo 
de Barranquilla a Puerto Colombia y arrojó un paquete postal en la plaza de Puerto Colombia (Aviación y Turismo, 2012).

Las demostraciones de Martin conducirían al interés de varios empresarios en constituir aerolíneas. Es así como el 5 de diciembre de 1919 se crea Avianca, bajo la razón social de SCADTA, Sociedad Colombo Alemana de Transporte Aéreo. La empresa fue constituida por tres alemanes: Werner Kammerer, Albert Tietjen, Stuart Hosie y cinco colombianos: Ernesto Cortissoz - el primer presidente-, Jacobo Correa, Arístides Noguera, Cristóbal Restrepo y Rafael Palacio (Saenz, 2010). Posteriormente, en julio de 1922, se volvería principal accionista Peter von Bauer, de origen austriaco, con un aporte de cien mil pesos colombianos (COP 100 000); lo que lo puso bajo el control de cuatro quintos de las acciones (Funding Universe, 2001; "Una historia de amor y dolor", 2004). SCADTA pasó varios meses preparando su primera ruta y tuvo incluso un accidente fatal, antes de que el 19 de septiembre de 1921 abriera la ruta Barranquilla-Girardot (Funding Universe, 2001). Le seguirían rutas entre Barranquilla, Girardot, Neiva, Cartagena y Santa Marta (Avianca Cargo, 2013; Funding Universe, 2001). Con una flota de seis F-13, SCADTA pronto comenzaría a emitir sus propias estampillas y a operar sus propias oficinas postales tras ganar su primer contrato de correo aéreo (Funding Universe, 2001). Para 1922, SCADTA había transportado al presidente Pedro Nel Ospina en misión oficial (Funding Universe, 2001). El año siguiente, en mayo, la compañía transportaría de Medellín a Bogotá COP 3,5 millones para contrarrestar una corrida bancaria del banco estatal (Funding Universe, 2001). El año de 1924, la compañía sufriría varios accidentes, incluyendo uno en que moriría su presidente Ernesto Cortissoz (Funding Universe, 2001).

Cuando SCADTA intentaba expandirse a Suramérica y el Caribe, la Pan American Airways se constituiría en su principal competidor, protegida por el Gobierno estadounidense ("Una historia de amor y dolor", 2004). El Gobierno estadounidense prohibiría a Avianca operar en las aguas del Caribe, ya que veía con malos ojos el que una compañía de capitales alemán y austriaco volara cerca del canal de Panamá ("Una historia de amor y dolor", 2004). SCADTA intentaría incursionar en Suramérica, pero al lograr Pan American la exclusividad de Perú, SCADTA quedaría relegada a Ecuador ("Una historia de amor y dolor", 2004). Ante la intensa competencia, Peter von Bauer, el nuevo presidente de la compañía, vendería sus acciones a la Pan American ("Una historia de amor y dolor", 2004).

Con el respaldo de Pan American, SCADTA se expandió doméstica e internacionalmente en la década de 1930: se abrieron las rutas Medellín-Barranquilla y Medellín-Bogotá, aunque requerían escalas y los accidentes eran comunes (Funding Universe, 2001). En 1931, se inauguró el primer servicio postal aéreo entre Bogotá y Nueva York (León, 2011). Finalmente, se reemplazaron los Ford trimotor por diez Boeing 247D y se desarrolló una red de aeropuertos de grama (Funding Universe, 2001). Luego, en 1939, vendrían los aviones DC3 de gran velocidad (Miranda, 2012). 
En 1940, se fundó Aerovías Nacionales de Colombia S.A., Avianca, de la fusión de SCADTA con el Servicio Aéreo Colombiano (Saco) (León, 2011). Debido a la Segunda Guerra Mundial, una serie de negociaciones llevaría a que Pan American se quedara con la mayoría de las acciones, el Gobierno nacional con otro tanto, y un grupo de accionistas minoritarios, entre ellos Mario Santo Domingo, con el resto ("Avianca: un vuelo turbulento", 2004).

\section{Evolución de la organización en función de la evolución de su contexto}

Evolución de la organización en función de la evolución de su contexto económico y político internacional: la Primera Guerra Mundial

Uno de los eventos que incidiría más sobre el surgimiento de SCADTA, hoy Avianca, es la Primera Guerra Mundial. El primer vuelo de los hermanos Wright había tenido lugar en 1903, pero no sería hasta el fin de la Primera Guerra Mundial que la aviación comercial tendría sus inicios en diversas partes del mundo, debido principalmente a que se vendían aviones militares a bajos precios y había gran oferta de expilotos militares (León, 2011). Como diría León Vargas (2011): "Hasta 1919 la aviación fue sólo un deporte de alto riesgo sin mayor utilidad práctica" (párr. 23). A Colombia habían llegado desplazados de la Primera Guerra Mundial varios de estos pilotos extranjeros (Mendoza, 1994). Por ejemplo, Knox Martin, quien influyó tanto con sus demostraciones en el surgimiento de las primeras empresas de aviación, había sido instructor de la fuerza aérea estadounidense y piloto de guerra en Francia (León, 2011). El auge de la aviación después del conflicto sería uno de los factores fundamentales para el desarrollo de SCADTA (Saenz, 2010).

Evolución de la organización en función de la evolución del contexto geográfico y económico-empresarial

Dos factores más del entorno fundamentales para el surgimiento y éxito de SCADTA fueron el factor geográfico y el factor económico-empresarial (Saenz, 2010).

La topografía de Colombia es sumamente abrupta y las mejores áreas de cultivo están en zonas de cordillera lejos de sus océanos. Por esta razón, hasta comienzos del siglo XX, el transporte colombiano era predominantemente de navegación fluvial y de transporte terrestre por mulas, con unos costos asociados altísimos (León, 2008). A pesar de la construcción de ferrocarriles hacia finales del siglo XIX, parte del atraso del país, en términos de sus exportaciones (por ejemplo, para 1912 Colombia solo superaba en sus exportaciones per cápita a Haití y Honduras en la región), se debía a las dificultades de transportar bienes sobre su orografía (León, 2008). 
Es aquí donde el olfato del empresariado colombiano y alemán descuella, puesto que con el advenimiento de la aviación fueron muchos los empresarios colombianos y alemanes que vieron una oportunidad de negocio. Los alemanes desplazados de la Primera Guerra Mundial buscaron formar las bases para un comercio internacional con su patria (Saenz, 2010), mientras que los empresarios colombianos vieron en lo que para la fecha parecían meras demostraciones acrobáticas, las bases para una naciente industria del transporte. Así, para 1923, por lo menos otras dos compañías colombianas de aviación fueron fundadas, lo que demuestra el sentido de oportunidad de los empresarios colombianos y alemanes; cuando cabe anotar, por ejemplo, que la Compañía Mexicana de Aviación tendría su inicio solo en 1921 y Lloyd Aéreo Boliviano, LAB, en 1925 (León, 2011). De hecho, el auge de la aviación en Colombia como negocio no se hizo esperar:Durante los veinte años que transcurrieron entre las dos guerras mundiales se fundaron en el país nueve compañías de aviación en las cuatro principales ciudades que para ese momento lideraban el desarrollo industrial de Colombia. Con excepción de Bucaramanga y Villavicencio: la primera lideraría el desarrollo en el oriente de Colombia y la segunda apoyada por la aviación se convertiría en la puerta de entrada a los llanos orientales. (León, 2011, párr. 26).

Para 1948, ya eran 27 las compañías fundadas, lo que representó un progreso significativo en la forma de transporte de pasajeros, de correo postal y de carga: Un viaje en barco a vapor entre Barranquilla y Puerto Berrío podía tomar entre ocho y 15 días, mientras que en avión tomaba ocho horas; un viaje entre Barranquilla y Bogotá, 14 días, mientras que tomaba diez horas en avión (León, 2011; Saenz, 2010).

Evolución de la organización en función de la evolución del contexto tecnológico

Otro factor decisivo del contexto para el desarrollo de SCADTA corresponde a la adopción de los avances tecnológicos. Creemos con Kliksberg (1975) que "la tecnología no es un factor autónomo al margen de la historia", sino que el surgimiento de las nuevas tecnologías ha sido exitoso solo cuando existe una "necesidad que las absorbiera y les diera aplicación" (pp. 120, 122). El inicio de SCADTA es un ejemplo claro de cómo los empresarios vieron la oportunidad de adoptar la tecnología aérea en función de sus intereses económicos, y desde un principio SCADTA estuvo a la vanguardia en adquisición tecnológica. Por ejemplo, en lugar de comenzar con aviones de madera, SCADTA utilizaba monoplanos enteramente en metal (como el Junker F-13) (Saenz, 2010). Y aunque hubo dificultades técnicas, estas se resolvieron eficientemente en aras de la supervivencia y eficiencia de la compañía:

Las dificultades técnicas, a pesar de todo, parecían insuperables. Cuando comenzaron a llegar los aviones, transportados en barco, se encontró que la gasolina existente en Colombia era diferente de la alemana, así que los motores tenían la tendencia a recalentarse. El ingeniero jefe, Schnurbusch adaptó radiadores de automóviles Hudson para solucionar el problema. La falta de 
repuestos apropiados hizo que en muchas ocasiones hubiera que recurrir al ingenio criollo para que las aeronaves levantaran vuelo.

Ciertamente viajar en avión en esa época no era la experiencia más tranquilizante. Solo era posible operar de día y los aviadores se orientaban con la navegación por contacto, esto es, mediante la observación de la superficie, por lo que los vuelos al interior del país seguían el curso del río Magdalena.

El segundo al mando no era un copiloto sino un mecánico. Cada vez que se presentaba una falla, el comandante simplemente acuatizaba, y los pasajeros debían esperar un rato con el aparato amarrado a la orilla mientras el mecánico hacía su trabajo. El frecuente reabastecimiento de combustible estaba a cargo de depósitos de canecas emplazadas convenientemente en la orilla del río cada cierto número de kilómetros. (Saenz, 2010, párr. 6-8)

Otras empresas no fueron tan eficientes en resolver sus problemas técnicos, ni en adquirir nuevas tecnologías (como los Boeing 247D o los DC3), lo que las llevó a desaparecer. Un ejemplo es la Compañía Colombiana de Navegación Aérea, liquidada a los dos años y tres meses de su fundación "agobiada por los accidentes y por el defecto de fabricación de los motores" (León, 2008, p. 211). Y aunque los accidentes también eran comunes en SCADTA, ya entre 1921 y 1925 SCADTA había movilizado exitosamente 5000 pasajeros, en parte con modernos aviones Dornier Wal, adquiridos con ayuda del Gobierno alemán (Saenz, 2010).

Evolución de la organización en función de la evolución del contexto económico y político internacional: imperialismo estadounidense y Segunda Guerra Mundial

Un aspecto del contexto de la organización que incidiría definitiva y negativamente sobre Avianca es el imperialismo estadounidense. El Gobierno estadounidense había firmado un acuerdo aéreo bilateral con Colombia el 23 de febrero de 1929, tan solo 20 días después de fundado PANAGRA, una compañía de Pan American Airways y W.R. Grace (Funding Universe, 2001). "PANAGRA, [la competencia de SCADTA], tenía finanzas más fuertes, más influencia, mejor equipo, y más publicidad que SCADTA" (Funding Universe, 2001, párr. 9). Ya desde 1925, SCADTA había comprado dos hidroaviones Dornier Wal con el propósito de abrir rutas al Caribe, pero los políticos estadounidenses le bloquearon el acceso a Nueva York y a Miami, para prevenir la intrusión de los intereses alemanes en el comercio estadounidense y en espera de que Estados Unidos consolidara su propia aerolínea Pan Am. SCADTA se vería forzado, debido a la intromisión estadunidense, a restringirse a Ecuador y a Panamá (Funding Universe, 2001).

Pero la injerencia estadounidense no pararía aquí. Gracias a la presión de PANAGRA y a la crisis económica mundial de 1929, Peter von Bauer se vería forzado a venderle secretamente sus acciones a Pan Am, en cabeza de Juan Trippe (Funding Universe, 2001; "Una historia de amor y dolor", 2004). La adquisición 
hostil dejaría a Pan Am con el 84,4\% de la compañía en febrero de 1930, a SCADTA sin su presidente von Bauer y a dos estadounidenses en la junta directiva (Funding Universe, 2001). Esta adquisición hostil coincide con la renovación de la flota de SCADTA con equipos británicos y estadounidenses.

La injerencia estadounidense se consolidaría durante la Segunda Guerra Mundial. El Gobierno de Estados Unidos tenía como política, una vez iniciada la guerra, identificar, investigar y perseguir a los ciudadanos alemanes en Latinoamérica. La idea de que la aerolínea SCADTA, con rutas cercanas al Canal de Panamá, estuviera liderada por capital alemán les molestaba a los estadounidenses. Aunque el presidente colombiano Eduardo Santos tenía simpatía por los alemanes, los estadounidenses lo presionaron para que revelara el pacto secreto con Trippe, nacionalizara las acciones alemanas de SCADTA y despidiera a todos los 80 alemanes de la compañía el 8 de junio de 1940 (Funding Universe, 2001; Reyes, 2011, pp. 167-169; Saenz, 2010). El Gobierno colombiano aprovechó su reciente inversión en Saco, un competidor menor, y lo fusionó con SCADTA en junio 14 para crear Aerovías Nacionales de Colombia (Avianca): Pan Am tendría el 64\% de la nueva empresa y el Gobierno colombiano el 15\% (Funding Universe, 2001).

Evolución de la organización en función de la evolución del contexto político nacional

Un último factor contextual al que es importante aludir en la evolución de SCADTA es el factor político. Ya en 1922, como mencionamos con anterioridad, el presidente colombiano Pedro Nel Ospina había acudido a SCADTA para llevar a cabo una misión oficial (Funding Universe, 2001). Sin embargo, es con el presidente Enrique Olaya Herrera que SCADTA consolida su posición en el ámbito político nacional. En 1932, Olaya Herrera convierte a SCADTA en la agencia de correo oficial del país, empleando 300 carteros (Funding Universe, 2001). La empresa debe devolver ese mismo año el favor político colaborando con el Gobierno nacional en las acciones militares de la guerra frente al Perú, cuando Perú intenta anexarse el Trapecio de Leticia (Funding Universe, 2001). Lo anterior evidencia la compenetración tan grande que existía entre esta empresa particular y las altas esferas políticas de la nación.

\section{Historia de Avianca: Parte II (1940-2014)}

"Los hechos"

En la década de 1940, la compañía Aerovías Nacionales de Colombia S.A., o Avianca, volaba a Quito (desde 1946), Lima, Panamá, Miami (desde 1947 sin 
escalas, en un DC-4 de Pan Am), Nueva York (desde 1949) y Europa (Lisboa, Roma y París desde 1950) (Aviación y Turismo, 2012; Funding Universe, 2001) y se había convertido en la principal aerolínea de Colombia ("Avianca: un vuelo turbulento", 2004). En febrero de 1944, Avianca era poseída en un 64\% por Pan American, en un $6 \%$ por el Gobierno colombiano, en un $10 \%$ por Peter von Bauer y en un $20 \%$ por otros colombianos, entre ellos, Mario Santo Domingo (Reyes, 2011). Al final de la década, la flota de Avianca estaba compuesta de aviones DC-3 y la mayoría de las bases para hidroaviones habían sido cerradas (Funding Universe, 2001).

Para 1951, Avianca entró en posesión de un Lockheed Constellation 0749 y un Super Constellation 1049L, "los aviones más grandes y rápidos de la época" (León, 2011). En 1956, Avianca llevaría a la delegación colombiana a los Juegos Olímpicos de Melbourne, Australia, un viaje de 61 horas contando las paradas para recargar combustible (Aviación y Turismo, 2012; León, 2011). La década de 1950 finalizaría con una Avianca con oficinas y campañas publicitarias en el exterior, con alianzas con otras aerolíneas y con una flota internacional de Lockheed Super Constellations (“Avianca: un vuelo turbulento", 2004; Funding Universe, 2001).

Con el paso del tiempo, Pan American tuvo una participación menor en la empresa: para 1968 su participación era de solo el 25\% y para 1975 del 11\% (Funding Universe, 2001; "Una historia de amor y dolor", 2004); entre tanto, diversos empresarios colombianos fueron ganando participación accionaria. En las décadas de 1960 y 1970, la compañía modernizó su flota. En octubre de 1960, voló a Nueva York con un Boeing 707 en leasing, y en enero de 1966 comenzó a volar jets Boeing 720 en las rutas nacionales (Funding Universe, 2001). Avianca operaría jumbo jets Boeing 747 desde diciembre de 1976, en especial en la ruta Bogotá-Frankfurt (Funding Universe, 2001).

En la década de 1980, Avianca experimentó un declive: para 1986 la empresa tenía deudas de USD 170 millones que tuvieron que ser renegociadas y su imagen pública se había perjudicado debido, en parte, a que sus vuelos a tiempo pasaron de ser el 66\% en 1986 a ser tan solo el 32\% en 1988. La empresa a su vez tenía problemas laborales y exceso de personal con 11000 trabajadores (Funding Universe, 2001). Además, una serie de incidentes afectaron su imagen: En noviembre de 1983 un Boeing 747 se estrelló cerca de Madrid; en marzo de 1988 un 727 se estrelló cerca de Cúcuta; en noviembre de 1989 una bomba del narcotraficante Pablo Escobar dirigida al entonces candidato presidencial César Gaviria Trujillo explotó en un Boeing 727 - el candidato no estaba a bordo y llegaría a ser presidente - , y en enero de 1990 un 707 se estrelló cerca de Nueva York por falta de combustible (Aviación y Turismo, 2012).

Hacia 1988 empezaron ciertas transformaciones administrativas: la compañía actualiza su sistema computarizado de reservas con IBM, adquiere el sistema de gestión de clientes Maxipars CRS de British Airways y gracias a despidos masivos reduce el personal a 5000 empleados para 1990 (Funding Universe, 2001). En 1994, inicia una reestructuración que intenta aumentar la productividad y reducir el número de niveles de gerencia de 13 a cinco y el número de directores de división de más 
de 50 a 26, al tiempo que se subcontratan varios servicios como el de alimentación a bordo (Funding Universe, 2001; Lima, 1998). Este mismo año, Avianca gana el control gerencial de la Sociedad Aeronáutica de Medellín, SAM, y de Helicópteros Nacionales de Colombia, HELICOL y funda la coalición estratégica entre Avianca, SAM y HELICOL que recibirá el nombre de Sistema Avianca (León, 2011). La aerolínea contaría para esta época con Boeing 767-200 y 767-300, Boeing 757, McDonnell Douglas MD-83, Fokker 50 y helicópteros Bell (“Una de las flotas", 1992). En diciembre de 1996, Avianca entraría en una alianza con American Airlines; y para 1997, Avianca contaría con varios nuevos acuerdos comerciales, como con SAETA de Ecuador y TACA de El Salvador (Funding Universe, 2001). Para ese mismo año de 1997, Avianca había reducido el total de sus empleados a solo 3000 y se lanzaría una nueva estrategia de marketing junto con SAM con productos como el servicio Expreso Nocturno a un precio sugerido para competir con los buses (Funding Universe, 2001). En diciembre de 1998, Avianca abriría el Centro de Conexiones de Bogotá, con 6000 conexiones semanales para Suramérica, Norteamérica y Europa, y una amplia oferta de frecuencias, horarios y destinos ("Bogotá, puerta de entrada al continente", 2000). Hacia el año 2000, la compañía invertiría USD 12 millones para actualizar sus servicios (Funding Universe, 2001).

Las décadas de 1980 y 1990 fueron, en retrospectiva, de pérdidas. En 1991, las pérdidas acumuladas desde la década de 1980 superaban los COP 32000 millones, y a pesar de buenos resultados, en especial en la primera mitad de la década de 1990, de 1998 a 2000 se habían perdido COP 414000 millones ("Una historia de amor y dolor", 2004). Estos resultados llevaron a Avianca a acercarse a su principal competidor, también en problemas, las Aerolíneas Centrales de Colombia, ACES, para tratar de salvar las dos compañías ("Una historia de amor y dolor", 2004). Ya desde finales de la década de 1990, Avianca (que incluía a SAM) se había acercado a ACES para una posible fusión ("Avianca: un vuelo turbulento", 2004). La fusión, que buscaba ahorros estimados de entre USD 60 y USD 100 millones anuales, finalmente se llevó a cabo en mayo 20 de 2002 bajo el nombre de Alianza Summa (Avianca Cargo, 2013; "Avianca: un vuelo turbulento", 2004). ${ }^{1}$

A pesar de todo, la fusión no tendría éxito y en 2003, cuando los prestamistas de ACES no accedieron a los acuerdos de pago ofrecidos, Juan Emilio Posada, el presidente de Alianza Summa, recibiría la orden de liquidar ACES ("Avianca: un vuelo turbulento", 2004). Avianca fue declarada en quiebra técnica en Colombia y se adelantó un proceso de reorganización y reajuste financieros acogiéndose al capítulo 11 de la ley de bancarrota de los Estados Unidos desde marzo 21 de 2003 (Barab, 2005; "Avianca, de la quiebra”, 2013). Para octubre de 2003, Avianca determinó que para una reorganización efectiva requería de nuevas inversiones de capital (Barab, 2005) y la Federación Nacional de Cafeteros y el Grupo Santo Domingo iniciaron contactos con LAN, Copa y Taca para una posible venta ("Avianca: un vuelo turbulento", 2004). Avianca había tenido pérdidas por COP 309000 millones en 2003 incluso con las ventajas del capítulo 11 ("Lo que el viento se llevó", 2004), y el 
prospecto de Avianca se veía empañado por un pasivo sobre los USD 300 millones y la existencia de fuertes disputas con los pilotos ("Avianca, de la quiebra", 2013). Entonces se presentó el empresario brasilero nacido en Bolivia Germán Efromovich, y tras cancelar el 10 de diciembre de 2004 USD 10 millones (de los USD 49 millones que le costó el 73\% de las acciones de la compañía), accedió a invertir sumas, junto con la Federación (La Federación le vendería a Efromovich su parte en 2006 por USD 25 millones), hasta alcanzar los USD 63 millones en los dos años posteriores para sacar adelante la empresa ("La venta de Avianca", 2013). Se inició así la reorganización esperada: se mejoró la planta de gestión humana, se negociaron mejoras en la productividad con los sindicatos, se rediseñaron las rutas, se mejoraron los procesos y se realizaron acuerdos (codeshares) con otras compañías aéreas (Miranda, 2012).

En 2005, Avianca cambia su denominación a Aerovías del Continente Americano S.A. (Avianca Cargo, 2013). Para junio de 2009, Avianca realiza una importante emisión de bonos en el mercado accionario colombiano por cerca de COP 500000 millones para, entre otras inversiones, modernizar la flota ("Avianca coloca bonos", 2009). En octubre de 2009, se anuncia la fusión con TACA, de El Salvador, una aerolínea con gran participación en el mercado centroamericano. TACA incluía participación en Lacsa, TACA Perú, Aviateca, Snasa, La Costeña e Isleña, y Avianca participación en Tampa Cargo y AeroGal (Avianca Cargo, 2013). El objetivo de la fusión era mejorar el posicionamiento estratégico y aumentar el crecimiento de ambas compañías; para esto se crea el Holding Avianca-TACA en el que Synergy Group, propiedad de Efromovich, queda con el $67 \%$ de participación y Kingsland Holding Limited, los propietarios de TACA, quedan con el 33\% ("Avianca y Sky Airline abren rutas", 2012). Durante 2010, empieza el proceso de reorganización administrativa para integrar las dos aerolíneas y lograr las sinergias esperadas (Avianca Cargo, 2013). En 2011, el holding Avianca-TACA emite acciones con dividendos preferenciales, pero sin derecho a voto, y recauda COP 2,8 billones (Avianca Cargo, 2013), y en junio 21 de 2012, la compañía ingresa a la alianza Star Alliance junto a miembros como Lufthansa y United Airlines (Star Alliance, que agrupa a 28 aerolíneas, es hoy la red mundial más grande e importante de aerolíneas en términos de vuelos diarios, cobertura y servicios) (Avianca Cargo, 2013; Star Alliance, 2014). En septiembre 19 de 2013, la compañía hace una oferta pública inicial de ADSs (títulos representados por ADRs, es decir, por títulos que representan compañías no norteamericanas en el mercado de valores norteamericano) por USD 100 millones con el objetivo de mejorar la flota (Calia, 2013). Desde la fusión con TACA, gracias a la cual la aerolínea llega a sumar 129 aeronaves, 12000 empleados y USD 3000 millones anuales en facturación, hasta la actualidad, Avianca ha incrementado su flota en 22 aeronaves (Arenas y Úsuga, 2013; "Los detalles del negocio", 2009); para el año 2013, Avianca atendía 23 millones de pasajeros en 730 vuelos diarios a más de cien destinos y transportaba 300000 toneladas de bienes al año ("La venta de Avianca", 2013; Karp, 2013). 


\section{Evolución de la organización en función de la evolución de su contexto}

\section{Evolución de la organización en función de la evolución del contex to tecnológico}

Ya desde la década de 1930, la aviación en Colombia se iría imponiendo en el transporte de pasajeros a los barcos y trenes (León, 2011). El entorno tecnológico jugaría un papel preponderante en esta tendencia, ya que Avianca siempre estuvo hasta la década de 1980, en la medida de sus posibilidades, al día en los avances tecnológicos a nivel mundial. Así, en la década de 1950, Avianca contaría con Lockheed Super Constellations ("Avianca: un vuelo turbulento", 2004; Funding Universe, 2001). En la década de 1960 y 1970, Avianca adoptaría la tecnología jet alquilando dos Boeing 707 y adquiriendo dos 737, el mismo tipo de avión que habían adquirido Lufthansa y Singapore Airlines (León, 2011). Para 1976, Avianca era la primera aerolínea latinoamericana que utilizaba de forma regular el Boeing 747 y para 1990, Avianca tenía dos Boeing 767-200 ER, avión considerado como uno de los más modernos del mundo (Avianca, 2013). Otra de las adopciones tecnológicas de Avianca más significativas la constituyó la construcción en 1981 de una terminal propia en Bogotá, el así llamado Puente Aéreo (Aviación y Turismo, 2012), el que con el tiempo se dedicaría exclusivamente a los vuelos nacionales (León, 2011). Esta continua actualización, al ir evolucionando el entorno tecnológico, mantuvo a Avianca competitiva, al menos hasta la década de 1980.

Una nueva etapa de adaptación tecnológica vendría después de la llegada de Efromovich. Entre 2005 y 2006, Efromovich invertiría USD 7 millones en la renovación del Puente Aéreo, lo que implicó mejoras en los counters, las salas de abordaje y la sala vip, y en 2006, Efromovich aumentaría la flota en diez aviones Fokker 100 destinados a ciudades intermedias colombianas (Pereira, Armenia, Bucaramanga y Pasto) ("El milagro de Avianca", 2007). La adaptación tecnológica con Efromovich también incluiría la modernización de los sistemas de gestión: en 2006, se adquirió el servicio ETS (Electronic Ticket Server) del sistema de distribución Amadeus, líder mundial en sistemas de distribución de viajes, lo que permitiría "la venta de tiquetes electrónicos a través de la web, agencias de viajes y otras aerolíneas, al mismo tiempo que [posibilitaría] ahorrar tiempos y costos en la emisión y distribución de tiquetes" (Miranda, 2012, p. 12). Otras innovaciones fueron la incorporación del sistema de código de barras bidimensional en los pasabordos y el establecimiento de kioscos de auto check-in (Miranda, 2012; "El milagro de Avianca", 2007). Igualmente, hubo mejoras en lo que se podría denominar tecnologías administrativas: una estructura tarifaria más avanzada, campañas como la Hora Feliz y Sorpresas Vuelan con Avianca para aumentar los vuelos en días de poca demanda, y el retorno del programa de acumulación y redención de millas Avianca Plus que en 2007 ya contaba con un millón de miembros ("El milagro de Avianca", 2007). Junto con cambios en las frecuencias de vuelo y la reapertura de nuevas rutas, también se adoptó otra nueva 
tecnología administrativa: nuevos esquemas de compensación variable para los empleados que castigaban, disminuyendo sus salarios, a quienes causaran retrasos en los vuelos. En parte gracias a estas reformas, el índice de cumplimiento mejoraría ostensiblemente hasta llegar en 2007 al 93,5\%, mientras que el índice de satisfacción del cliente llegaría al $90 \%$ en esa misma fecha ("El milagro de Avianca", 2007). En 2007, la empresa adquiriría 10 aeronaves Boeing 787 Dreamliner y 41 Airbus, aeronaves que logran reducir el consumo de combustible en $20 \%$ y los costos totales de funcionamiento en 10\% (Miranda, 2012). Igualmente se adoptaría el sistema de entretenimiento multimedia a bordo para las principales rutas largas y con base en la plataforma ETS se patrocinarían convenios IET (Interline Electronic Ticket) que permiten emitir tiquetes electrónicos con itinerarios compartidos con otras aerolíneas (Miranda, 2012). En 2009 habría otra renovación tecnológica: una nueva sede administrativa en un edificio inteligente en la ciudad de Bogotá con capacidad para 2000 empleados (Miranda, 2012). Todas estas adopciones tecnológicas, que se refieren no solamente a la industria aeronáutica, sino también a nuevas tecnologías de gestión, constituirían un factor coadyuvante fundamental en el resurgimiento de Avianca como compañía rentable en la era Efromovich.

Evolución de la organización en función de la evolución del contexto económico: el monopolio de Avianca

Avianca se desarrollaría en un entorno económico que facilitaba e incluso impulsaba los grandes monopolios capitalistas. Desde la década de 1940, Avianca constituyó un monopolio. Para mediados de esa década, Avianca era propietaria de casi todos los aeropuertos del país y prohibía su uso a otras aerolíneas (Reyes, 2011, pp. 169-171). Y aunque surgieron pequeñas aerolíneas y taxis aéreos, Avianca seguiría siendo la aerolínea dominante en las décadas de 1960 y 1970 (Funding Universe, 2001), gracias en buena parte al músculo de poder económico de sus dueños - como describiremos en el apartado siguiente - . Tras la Segunda Guerra Mundial, surgieron varias aerolíneas aprovechando la disponibilidad de aviones, como Lloyd Aéreo Colombiano (LAC), Taxi Aéreo de Santander (TAXADER), Líneas Aéreas La Urraca y Aerovías Cóndor de Colombia, Ltda. (Aerocóndor), pero la mayoría fracasaron ante las intenciones monopolistas de los dueños de Avianca (Funding Universe, 2001). Por ejemplo, en la década de 1950, Avianca absorbería a sus competidoras Sociedad Aérea de Tolima (SAETA) y Líneas Aéreas Nacionales, S.A.(LANSA). No sería sino hasta la desregulación de 1991 - que describiremos en otro apartado - , que Avianca vería amenazada su hegemonía en Colombia.

No obstante, incluso cuando Avianca intentó fusionarse con ACES en 2001, el superintendente de Industria y Comercio hizo calcular el índice Herfindahl-Hirschman o HHI que sirve para determinar el poder de un monopolio en el mercado (Reyes, 2011, pp. 326-328) y los resultados confirmaron su posición monopolista. 
Los mercados no concentrados tienen un HHI por debajo de 1500 ; los mercados moderadamente concentrados, un HHI entre 1500 y 2 500; los mercados muy concentrados, un HHI por encima de 2500 (U.S. Department of Justice \& the Federal Trade Commission, 2010). Antes de la fusión, el HHI de las operaciones nacionales en Colombia era de 2600 , después de la fusión llegaría a 4 807, y saltaría de 1944 a 2830 para las rutas internacionales (Reyes, 2011, pp. 326-328). Y a pesar de las objeciones del superintendente, y tras su salida forzada por el Grupo Santo Domingo, el entorno económico-político favoreció la fusión y el monopolio de Avianca se consolidaría, aunque esto no sería suficiente para contrarrestar las ineficiencias de la compañía.

Evolución de la organización en función de la evolución del contexto económico: la disputa por Avianca entre grandes grupos empresariales

El contexto económico colombiano y global durante la segunda parte de la historia de Avianca estaría caracterizado por la dominación económica de grandes conglomerados en cabeza de contados líderes capitalistas. Avianca se convertiría precisamente en el foco de poderosas disputas por su control entre algunos de los conglomerados económicos que marcarían la historia económica de Colombia desde fines de la década de 1960. La evolución de estos conglomerados económicos, con sus intereses y motivaciones particulares, marcaría a su vez los rasgos fundamentales de la evolución de la compañía.

Comenzando a finales de 1960 a hacer sustantivas adquisiciones, hacia 1975 el principal accionista de Avianca era Jaime Michelsen Uribe, del Grupo Gran Colombiano (“Avianca: un vuelo turbulento", 2004; "Una historia de amor y dolor", 2004). En 1975, Michelsen le vende su participación al urbanizador Fernando Mazuera Villegas por USD 1,6 millones, quien consigue estos fondos al vender las urbanizaciones bogotanas Milenta y Madelena a su competidor Luis Carlos Sarmiento (“Avianca: un vuelo turbulento", 2004). Entonces, dos de los accionistas, pesos pesados de la nación, Julio Mario Santo Domingo (junto con Pan American, otro de los accionistas) y Carlos Ardila Lülle se aliaron para evitar que Mazuera controlara la junta directiva (Reyes, 2011, pp. 169-171). ${ }^{2}$ Debido a la manera como se elegían los miembros de la junta y a que los contradictores de Mazuera recurrían a los así llamados "poderes de ventanilla", ${ }^{3}$ ni en 1976, ni en 1977, Mazuera pudo controlar la junta, incluso a pesar de contratar a Fernando Londoño (futuro Ministro de Interior y Justicia de 2002 a 2004) en su defensa y a pesar de que Londoño denunció una inflación de las utilidades de la compañía para repartir más dividendos y ganar así Santo Domingo accionistas menores mediante los poderes de ventanilla (Reyes, 2011, pp. 169-171). Pedro "el Negro" Bonnet, en defensa de Santo Domingo, sostendría que no había inflación de las utilidades, sino que había tan solo una utilidad ocasional por venta de aviones ("Una historia de amor y dolor", 2004). En respuesta, Fernando 
Londoño intentaría conseguir, infructuosamente, la lista de los accionistas menores de la compañía para poder contrarrestar también los poderes de ventanilla de sus antagonistas; pero finalmente Mazuera cedería ante Santo Domingo y le vendería sus acciones (Reyes, 2011, pp. 173-175), quedando Santo Domingo como principal accionista y Ardila Lülle como el segundo mayor accionista ("Una historia de amor y dolor", 2004). Bob Booth, consultor aeronáutico de Miami especialista en Latinoamérica, diría en 1992 que Avianca era "una de las aerolíneas más fuertes y mejor manejadas del mundo, pero las cosas cambiaron cuando el conglomerado de Santo Domingo tomó el poder de la empresa" (Reyes, 2011, pp. 175-176).

Hacia mediados de 1985, la lucha, ahora entre Santo Domingo y Ardila Lülle, llegaría a un punto supremo. El periodista e investigador Gerardo Reyes (2011) describió la situación así:

\begin{abstract}
Avianca estaba dividida en dos bandos irreconciliables: los seguidores de Ardila Lülle y los fieles de Santo Domingo. La empresa no funcionaba. Algunos ejecutivos ignoraban a otros porque no hacían parte de su equipo, y las juntas directivas terminaban siendo intensos torneos de pulso donde los sectores en pugna se pedían cuentas de las cosas más triviales. Ardila prohibió servir gaseosas que no fueran producidas por [su empresa] Postobón en los aviones de Avianca. Los representantes de Santo Domingo trataban de boicotear la medida leyendo cartas en la reunión de juntas directivas de pasajeros que se quejaban por la falta de Coca-Cola en los aviones. A lo que los directivos de Ardila respondían que podían tomar Pepsi Cola [franquicia de Ardila], que sí estaba permitida. Toda esta contienda de corbatas sueltas se intensificó y finalmente desembocó en el rompimiento de las relaciones entre los dos accionistas. El detonante del conflicto fue una supuesta traición. Julio Mario Santo Domingo estaba convencido de que uno de sus amigos de Barranquilla, Andrés Cornelissen, presidente de Avianca y a quien identificaba como del bando de Ardila, lo engañó. ( pp. 180-182).
\end{abstract}

Así, aunque Cornelissen tenía el aval del Gobierno y de la banca internacional por su apropiada gestión, en especial en un momento en que la empresa tenía una deuda externa de USD 171 millones (Reyes, 2011, pp. 182-184), Cornelissen tuvo que renunciar acusado, incluso legalmente, de obtener comisiones por el negocio de alquiler de aviones a Avianca (Reyes, 2011, pp. 184-186). Los abogados de Cornelissen intentaron acusar infructuosamente a Santo Domingo de recibir también comisiones por la práctica común en Avianca de alquilar aeronaves mediante leasing (Reyes, 2011, pp. 186-190). Para esta época, Ardila controlaba dos renglones de siete de la junta directiva; Santo Domingo, tres; y el Gobierno, dos, pero el Gobierno se abstenía de tomar posiciones, lo que favorecía a Ardila (Reyes, 2011,pp. 194-196). Al llegar a un punto muerto las negociaciones para nombrar a un sucesor de Cornelissen, Augusto López Valencia, en representación de Santo Domingo, le dio a Ardila un ultimátum: "O nos compran o nos venden, pero aquí no cabemos los dos" (Reyes, 2011, pp. 196-198). A pesar de que finalmente se nombró a Benjamín Martínez por acuerdo de Ardila y Santo Domingo (Reyes, 2011, pp. 196-198), este no aceptó el cargo "lo que generó un enfrentamiento por hacerse a la administración de la 
empresa y se detuvo el desembolso de un préstamo de mil millones de dólares... condicionado a la solución del problema" (Rodríguez y Duque, 2007, p. 143). Con el paso del tiempo, Ardila le vendería a Santo Domingo su 31\% de acciones que había comprado por COP 800 millones a su valor en bolsa de COP 150 millones, dejando a Santo Domingo con el control absoluto de la compañía - en un momento en que la empresa venía perdiendo un promedio de COP 2500 millones al año- (Rodríguez y Duque, 2007; “Una historia de amor y dolor", 2004).

Tras la salida de Cornelissen, pasaron por Avianca nueve presidentes durante una década, entre otros, Álvaro Jaramillo quien salió luego de venderle unos terrenos a Intercontinental con quien Avianca competía ("Una historia de amor y dolor", 2004). Solo se logró cierta estabilidad cuando Gustavo Alberto Lenis Steffens asumió la presidencia entre 1993 y 2000 ("Avianca: un vuelo turbulento", 2004). Precisamente la fusión de 1994 con la Sociedad Aeronáutica de Medellín, SAM, se facilitó gracias a que SAM era parte del Grupo Santo Domingo desde vieja data ("Una historia de amor y dolor", 2004).

Una de las preguntas abiertas es por qué Santo Domingo se aferraba a una empresa que durante 20 años generó pérdidas, pérdidas por las que Santo Domingo pedía continuamente ayuda al Gobierno (Reyes, 2011, pp. 256-258). Un análisis financiero de 1992 de uno de los sindicatos de trabajadores de la aerolínea, Sintrava, concluía que la "función [de Avianca], de acuerdo a los balances, está en generar ganancias a terceros y reinvertir estas utilidades bajo otra modalidad", en lugar de repartir utilidades (Reyes, 2011, pp. 256-258), lo que podría describirse apropiadamente como tunneling (C. Rodríguez, comunicación personal, 31 de enero, 2014), "la transferencia de recursos de una compañía a los accionistas que la controlan" (Johnson, La Porta, Lopez-de-Silanes y Shleifer, 2000, p. 22). Por ejemplo, Sintrava concluía, de acuerdo con Reyes (2011), que "Avianca se nutría de las reservas de sus prestaciones legales, que ascendían a 60 millones de dólares, 24 veces superior a los aportes de los accionistas" (pp. 258-260). Otro estudio financiero, de 1995, por parte de un profesor de la Universidad Nacional de Colombia, tenía entre sus conclusiones que:

\footnotetext{
La estructura de costos actuales que maneja Avianca presenta gastos crecientes que favorecen a las compañías financieras extranjeras que financian a través de operaciones de arriendo con opción de compra de las aeronaves con las cuales presta sus servicios. Esto ha dado como resultado que casi $15 \%$ de los costos de operación se trasladen a los capitalistas internacionales. (Parra, 1995, pp. 32-33).
}

Ese mismo estudio afirmaba que "el insuficiente capital de trabajo de la compañía la obliga a recurrir al crédito de la banca comercial, que por su elevado costo, reducen [sic] consecuencialmente su rentabilidad, sumiéndola en un círculo vicioso" (Parra, 1995, p. 33). Todo lo anterior soporta la idea de que, debido a los intereses de quienes controlaban Avianca, los inversionistas financieros estaban entre los más beneficiados con sus operaciones. Resulta un hecho respecto a las operaciones de arriendo, por ejemplo, que para 1991 Avianca solo contaba con cinco aviones propios 
y 17 eran arrendados, mientras que en 1980 poseía 18 aviones y 17 eran alquilados (Reyes, 2011, pp. 257-259). También es un hecho que después de la fusión con ACES se intentaron renegociar en cierto momento los leasings porque la empresa sentía que estaban por encima de los valores de mercado (Barab, 2005). Y es un hecho también que la salida de Cornelissen se hizo en medio de acusaciones mutuas entre Cornelissen junto a su amigo Corriea y Santo Domingo por apropiaciones indebidas mediante comisiones respecto a los leasings y porque existió una compañía “de papel” asociada a los leasings, Norasco, a la que Avianca le pagaba USD 5000 mensuales (Reyes, 2011, pp. 177-191). Quizás nunca se sabrá si quien recibía realmente las comisiones de los leasings era Corriea, Cornelissen o el Grupo Santo Domingo, pero oficialmente Norasco estaba a nombre de Corriea (aunque era manejada por Avianca) y los tribunales a los que recurrió el Grupo Santo Domingo condenaron a Corriea, después de muerto (Reyes, 2011, pp. 188-191). Es muy probable, sin embargo, que los intereses del entorno económico de Avianca en cabeza del Grupo Santo Domingo conspiraran en contra de la organización y a favor de terceros.

El papel del Grupo Santo Domingo tras la fusión de ACES también ha despertado ciertas dudas sobre si el Grupo Santo Domingo se aprovechó de ACES. La fusión, que fue un fracaso, buscaba sinergias estimadas de hasta USD 100 millones anuales mediante:

\footnotetext{
La integración de itinerarios, de tarifas y de operación, el intercambio de aeronaves y el uso [conjunto] de la infraestructura aeroportuaria y de puntos de venta... la negociación conjunta con proveedores y terceros, la prestación recíproca de servicios, la adopción de mejores prácticas y la racionalización y optimización del uso de los recursos. (“Avianca: un vuelo turbulento", 2004, párr. 19-20).
}

Miranda Marín (2012) sugiere que fue el cambio de las marcas Avianca, SAM y ACES a Alianza Summa, junto con el cambio de logotipo, lo que le restó posicionamiento a la nueva compañía. Diez años después de la fusión, el presidente de Alianza Summa, Juan Emilio Posada, explicaría que el Grupo Santo Domingo y la Federación de Cafeteros, socios iguales después de la fusión, simplemente no tenían recursos para invertirles a las dos aerolíneas por lo que se decidió salvar la marca más sólida e internacionalizada ("Avianca: un vuelo turbulento", 2004). No obstante, ya que ACES fue liquidada y Avianca se acogió al capítulo 11 de la ley de bancarrota de los Estados Unidos, por mucho tiempo se especuló que se "había sacrificado una buena empresa de los cafeteros por salvar la aerolínea de Santo Domingo" ("La venta de Avianca", 2013, párr. 8). Aunque también es cierto que Julio Mario Santo Domingo había invertido cerca de USD 300 millones para salvar Avianca, dinero ${ }^{4}$ que, en principio, nunca recuperó ("Una historia de amor y dolor”, 2004).

Tras acogerse al capítulo 11, llega a la compañía un nuevo grupo empresarial, esta vez extranjero, que llegaría a conocerse como Synergy Group. Este grupo es dirigido por el brasilero nacido en Bolivia Germán Efromovich, un empresario hecho por su propio esfuerzo que había sido vendedor de enciclopedias, traductor 
de telenovelas mexicanas al portugués y profesor (Mejía, 2013). Efromovich era un operador de servicios de pozos petroleros de Petrobras S.A. cuando ingresó al negocio de la aviación por casualidad, un día en que uno de sus subcontratistas saldó su deuda con él con aviones (Mejía, 2013). Esto marcaría el inicio de la aerolínea Ocean Air en 1998, inicialmente un servicio de taxi aéreo para compañías petroleras (Dias, 2013). La jugada maestra de Efromovich para consolidarse en el negocio de la aviación es precisamente la adquisición de Avianca. El estilo informal de Efromovich contrasta con el estilo rimbombante de Santo Domingo y sus abogados: Efromovich se introduciría él mismo a la Corte del Distrito Sur de Nueva York donde, sin abogados, ni banqueros de inversión, sin auditoría jurídica y contable o sin un proceso de due dilligence $\square$ es decir, sin mandar a valorar la compañía o sus activos (Hoskisson, Hitt y Ireland, 2004, pp. 251) $\square$, Efromovich se comprometería a invertir en Avianca: una empresa que llevaba 20 meses en el capítulo 11, a la que solo le quedaba en caja dinero para operar por diez días, con pasivos de más de USD 300 millones y continuas "operaciones tortuga"; es decir, lo que en otras palabras se conoce como una "inversión colilla": una empresa que todos dan por muerta, pero que se compra con la esperanza de encenderla ("Avianca: un vuelo turbulento", 2004; "El milagro de Avianca", 2007).

Efromovich se adelantaría así a otros interesados que seguían titubeando después de meses de investigaciones como Continental, Copa, Taca y Lan-Chile, los cuales se abstuvieron de superar la oferta del brasilero. De hecho, su jugada fue tan inesperada que tomaría por sorpresa incluso al presidente de Avianca, Juan Emilio Posada, y a Violy McCausland que fungía de banquera de inversión para el Grupo Santo Domingo (“Avianca: un vuelo turbulento", 2004; "Lo que el viento se llevó", 2004). Curiosamente, y contrario a lo que sucedía bajo Santo Domingo, con Efromovich, bajo la presidencia de Fabio Villegas, la compañía pronto mostró resultados y para 2005 había multiplicado sus ingresos por seis (“Avianca, de la quiebra”, 2013). Hacia 2006, Avianca tenía utilidades netas de USD 20 millones gracias, entre otras razones, a la confianza del público ante la renovación del interior de la flota, la reapertura de rutas previamente cerradas, el incremento de las frecuencias y la adquisición de nuevos aviones ("El milagro de Avianca", 2007). Un analista sugiere que, a diferencia de Santo Domingo que estaba demasiado diversificado y por ende no se preocupaba realmente por Avianca, Efromovich sí se preocupaba por que hubiera una estrategia de largo plazo para la compañía, aunque también se benefició del boom de la economía ("El milagro de Avianca", 2007). No deja de sorprender, sin embargo, cómo el cambio de conglomerado económico dueño significó un giro de 180 grados para la compañía ante un entorno aparentemente similar; esto sugiere la gran relevancia de los intereses profundos de quienes establecen las respuestas a las exigencias del entorno.

En este contexto optimista entra al escenario el último grupo económico involucrado con Avianca: los Kriete, dirigido por Roberto José Kriete Ávila, con inversiones en aviación, bienes raíces, agroindustria y hoteles (Ávila, 2014), y 
dueños de TACA, una aerolínea salvadoreña con operaciones en Centroamérica y Perú que incluía también a la mexicana Volaris (Santamaría, 2009). Efromovich y Kriete fusionan Avianca con TACA en un nuevo holding, Avianca-Taca, en el que el Synergy Group (propietario de Avianca) quedó con un 67\% de participación y Kingsland Holding Limited (propietario de TACA) con un 33\% (“Avianca y Sky Airline”, 2012). Juntas las dos compañías sumaban USD 3000 millones en facturación, 90 destinos en el continente americano (más destinos que cualquier otra aerolínea en la región), 12000 empleados y 129 aviones ("Los detalles del negocio Avianca-Taca", 2009). El holding es conocido hoy, después de la unificación de las dos marcas, como Avianca Holdings y representa la segunda compañía holding de aviación más grande de Latinoamérica, después de LATAM Airlines Group (Avianca Holdings S.A., 2013). La llegada de los Kriete marca así la multinacionalización final de la compañía hasta el día de hoy.

Terminamos esta subsección comentando cómo la evolución de Avianca en esta segunda parte de su historia sucede condicionada, tal y como lo hemos presenciado, al resultado de las sucesivas contiendas y alianzas entre los capitalistas más diversos y sus grupos económicos: Jaime Michelsen Uribe, Fernando Mazuera, Carlos Ardila Lülle, Julio Mario Santo Domingo, Germán Efromovich y Roberto José Kriete Ávila. Muchas veces, como ocurría con Santo Domingo, los intereses de la compañía ocupaban un segundo lugar respecto a los intereses del grupo; en otras ocasiones, como con Efromovich, los intereses de la compañía y del grupo iban al unísono. El contrapunto entre la motivación última del dueño y las necesidades de la gestión de la organización permitió, en ciertas épocas, lo mismo que evitó, en otras, el que la compañía pudiera adaptarse a los demás factores de su entorno.

Evolución de la organización en función de la evolución del contexto políticolegal: la desregulación y apertura del mercado y las leyes sobre pasivo laboral

Después de los gobiernos neoliberales de Margaret Thatcher en Reino Unido y especialmente de Ronald Reagan en Estados Unidos, se extendió durante la década de 1990 el Consenso de Washington y el neoliberalismo a lo largo de Latinoamérica (George, 1999; Kelly, 2008). En Colombia, el presidente César Gaviria Trujillo consolidaría durante su mandato neoliberal la así llamada Apertura Económica iniciada por su antecesor Virgilio Barco Vargas (Santos, 2009, p. 93). Esta incluiría la desregulación de 1991 del transporte aéreo.Así, aunque incluso hasta 2001 Avianca seguía constituyendo un monopolio, sin lugar a dudas la compañía recibiría un espaldarazo legal cuando el Gobierno colombiano aprueba "la liberalización de 1991”, un legislación mediante la cual el mercado de transporte aéreo colombiano sería desregulado (Funding Universe, 2001). La liberalización le abriría las puertas a 25 aerolíneas internacionales y a algunos nuevos emprendimientos domésticos (Funding Universe, 2001), y debido a ella, Aces e Intercontinental (nacionalmente) 
y Mexicana, Alitalia, KLM y British Airways (de y hacia Bogotá desde el exterior) entrarían a competir ferozmente con Avianca en el mercado de pasajeros; y ARCA, Aerosucre, Aces y las estadounidenses Challenge y Arrow Air, en el mercado de carga (Funding Universe, 2001). Intercontinental, por ejemplo, cobraría $20 \%$ menos en sus tiquetes que Avianca, y de 1992 a 1993 crecería 70\% en número de pasajeros transportados, mientras que AeroRepública, que empieza sus operaciones en 1993 con tarifas más bajas que Avianca, lograría crecer $80 \%$ en 18 meses en número de pasajeros transportados (Lima, 1998).

Para 1997, Avianca había pasado de una participación del mercado de 61,3\% en 1990 a solo $41 \%$ y oficialmente la compañía se quejaba del daño sufrido por los acuerdos bilaterales con otros países (Funding Universe, 2001; Lima, 1998). De hecho, la reestructuración de la compañía de 1994 fue en parte una respuesta a las cambiantes condiciones del mercado (Lima, 1998). Según Flight International, la capacidad crecía más rápido que la demanda e incluso el presidente de Avianca Gustavo Alberto Lenis Steffens llegó a comparar la situación en Suramérica - con aerolíneas como Ecuatoriana en cese de operaciones o la venezolana Viasa y la chilena Ladeco en la bancarrota - a la situación en Estados Unidos y Europa al comienzo de sus propias desregularizaciones (Funding Universe, 2001). Así, Avianca se vio sumamente afectada por este cambio político-legal intempestivo y tuvo que reajustarse a las nuevas condiciones del entorno posliberalización.

Otro aspecto político-legal que afectaría a la compañía adquiere relevancia cuando esta se acoge a la quiebra técnica o Ley 550 en Colombia y al capítulo 11 en Estados Unidos. El capítulo 11 permite a una compañía reorganizarse y refinanciar sus obligaciones, al tiempo que se detienen todas las acciones de los acreedores para recoger sus pagos en dinero o en bienes (Barab, 2005). Sin embargo, Smith, Gambrell \& Russell, la firma de abogados contratada por Santo Domingo, tendría muy claro desde el principio que al tiempo que Avianca se acogía al capítulo 11, debía también honrar sus deberes contractuales con los acreedores en Colombia, aunque el doble proceso de quiebra sería intrínsecamente difícil (Barab, 2005). El arreglo alcanzado "hizo posible la protección de las deudas laborales, el pago a proveedores y liquidar las deudas con entidades estatales como la DIAN, el Seguro Social y la Aerocivil" (Miranda, 2012, p. 11); pero fue la interpretación de la legislación laboral colombiana la que implicaría el mayor reto para Avianca. Valores Bavaria, el holding de Santo Domingo, había asumido previamente garantizar el pago de 3000 jubilados de tierra de la aerolínea, por un valor estimado de USD 120 millones ("Lo que el viento se llevó", 2004). La pregunta legal abierta en ese momento fue si Valores Bavaria debería seguir respondiendo por ese pasivo una vez declarado el estado de insolvencia. La revista Semana explicaba la situación de esta manera:

En Colombia la normatividad reciente ha determinado que cuando una empresa es subsidiaria de un grupo económico, en algunas circunstancias la matriz tendría que responder por las obligaciones laborales contraídas. Las circunstancias a que se refiere es cuando la insolvencia es resultado de acciones de la 
matriz y no de la empresa subsidiaria. En el caso de Avianca, es obvio que los problemas financieros que existen obedecen a problemas propios del sector aeronáutico. Por ejemplo, los costos del combustible, los seguros y el leasing de los aviones se pagan en dólares mientras que un porcentaje alto de los ingresos de Avianca es generado en pesos.

Obviamente estos problemas no se le pueden adjudicar a ninguna matriz. Sin embargo, como en Colombia el tema pensional es de una sensibilidad política tan grande, existe siempre el riesgo remoto de alguna interpretación jurídica desfavorable. En todo caso es indudable que en el país existe una incertidumbre jurídica sobre el resultado de los litigios laborales. Así sucedió en el caso de la Federación Nacional de Cafeteros cuando, con motivo de la liquidación de la Flota Mercante Gran Colombiana, la Corte Constitucional determinó que los cafeteros tenían que correr con los pasivos pensionales. ("Lo que el viento se llevó”, 2004, párr. 15-16).

Hasta finales de 2003, incluso el Congreso tuvo que intervenir, incluyendo la extensión del plazo para el pago de los pasivos laborales asumidos por Valores Bavaria, de 2012 a 2023. El hecho es que aunque Valores Bavaria tuvo que continuar asumiendo su compromiso pensional con los trabajadores en tierra, para 2011 Santo Domingo había recurrido a sus abogados para demandar a Avianca por cerca de COP 361000 millones aduciendo que su compromiso inicial era el de pagar COP 350000 millones y que, en cambio, ya había pagado COP 552528 millones (KienyKe, 2011). De esta manera, la ambigüedad legal del entorno colombiano terminó por impactar en la situación económica de Avianca en su momento más difícil.

\section{Evolución de la organización en función de la evolución del contexto político}

El nexo de Avianca y su coevolución con los destinos de los líderes políticos de la nación se esbozan muy bien en tres episodios selectos.

En el primer episodio, en 1942, cuando Mario Santo Domingo y otros barranquilleros como José Blanco, J. Montes y R. Obregón querían que la sede de la aerolínea continuara en Barranquilla, ellos no solo se aliaron con los medios (prensa y radio) y lograron una huelga general, sino que lograron que el concejo municipal amenazara con "el paro total de actividades comerciales, industriales, de transporte aéreo, fluvial y terrestre, y además [con que] se cerrarían almacenes, fábricas y oficinas privadas y públicas" (Reyes, 2011, pp. 167-169). Finalmente, se llegó a un arreglo en el cual la sede principal quedaría en Barranquilla y la presidencia en Bogotá.

El otro episodio que denota la complicidad de Avianca con las altas esferas del poder vendría en 1942, cuando el presidente colombiano Julio César Turbay pidió prestado el jumbo de Avianca para su gira por Europa en la que pretendía legitimar su persecución política, judicial e incluso sus torturas a los sospechosos de pertenecer o apoyar al M-19, incluyendo a artistas, periodistas y dirigentes de izquierda. No solo el presidente de Avianca, Ernesto Mendoza Lince, cedió el jumbo por 20 días e hizo 
parte de la comitiva presidencial, sino que Avianca asumió el lucro cesante (estimado en cerca de USD $300000 \mathrm{al} \mathrm{mes)} \mathrm{(Reyes,} \mathrm{2011,} \mathrm{pp.} \mathrm{173-175).}$

En el tercer episodio, el "poder político" de Avianca, o más específicamente de sus dueños, se vería en el manejo que hubo de la denuncia - que hemos tratado en otro aparte - del superintendente de Industria y Comercio, Emilio José Archila Peñalosa, cuando se opuso en 2001 a la fusión de Avianca con ACES arguyendo prácticas monopolistas. Los abogados de Avianca rápidamente formaron un caso en su contra, especialmente con base en sus declaraciones en ciertas entrevistas. Aunque "Archila sostuvo que el 25 por ciento de esas pruebas no tenían ni una sola frase de él; más del 80 por ciento se refirieron a declaraciones anteriores [que no se relacionaban con el caso], y de los tres artículos restantes [artículos de prensa citados por los abogados] dos no contenían declaraciones suyas y uno decía una perogrullada" (Reyes, 2011, pp. 328-329), el ministro de Desarrollo Económico, Eduardo Pizano de Narváez, concluyó que el superintendente estaba impedido para objetar la fusión, después de lo cual Archila renunció a su cargo. La fusión se daría en 2002 ("Una historia de amor y dolor", 2004).

Con el profundo involucramiento político de Avianca y sus dueños con el Gobierno nacional, no deja de ser un poco paradójico y contradictorio que en 1990 oficiales de la compañía culparan al Gobierno de falta de procedimientos de seguridad en los operadores de bajo costo, de infraestructura inadecuada y de inestabilidad política al justificar el pobre desempeño de su compañía (Funding Universe, 2001).

Evolución de la organización en función de la evolución del contexto social: las relaciones laborales y los sindicatos

El siglo XX en Colombia se ha caracterizado por una gran inequidad social, inequidad que en gran parte es el reflejo de la inequidad salarial y el desempleo (Urrutia, 1982). En respuesta a la inequidad salarial y a las difíciles condiciones laborales, el sindicalismo surge en Colombia alrededor de la década de 1910 (Urrutia, 1982). Precisamente, las condiciones sociales de los trabajadores de Avianca también configuraron en cierta medida su evolución, en especial si se tiene en cuenta que la empresa pasó de 11000 empleados en la década de 1980 a 3000 en la década de 1990 (Funding Universe, 2001). En Avianca las tensiones entre la administración y sus empleados se remontan a las décadas de 1960 y 1970 (y se extienden hasta el día de hoy). Algunos de los sindicatos de la compañía han sido "Sintrava (trabajadores de base), Acma (Asociación Colombiana de Mecánicos de Aviación), Acav (Asociación Colombiana de Auxiliares de Vuelo), Acdac (Asociación Colombiana de Aviadores Civiles) y Acdiv (Asociación Colombiana de Ingenieros de Vuelo)" ("Avianca: un vuelo turbulento", 2004, párr. 10). En muchos momentos de la historia de la empresa han sido populares las "operaciones tortuga" o "reglamento" que consisten en ceñirse al pie de la letra en los manuales de operación en detrimento del servicio y 
causando sobrecostos (“Avianca: un vuelo turbulento", 2004). Las convenciones que han firmado los diferentes sindicatos, justas o no, y el pasivo laboral han sido unos de los factores decisorios que frenaron un mejor desempeño y el crecimiento de la compañía ("Avianca: un vuelo turbulento", 2004). Por ejemplo, el pasivo laboral por sí mismo fue decisivo en la bancarrota de la empresa: de los USD 300 millones que tenía la empresa de pasivos cuando entró en bancarrota, USD 250 millones pertenecían a la deuda pensional: una mitad correspondía al personal en tierra y la otra mitad a los pilotos ("El milagro de Avianca", 2007).

Incluso después de la adquisición de la empresa por parte de Efromovich, los problemas laborales han persistido. Por ejemplo, Avianca recientemente enfrentó, durante 21 días, una huelga de pilotos, a saber, la "operación cero trabajo suplementario", finalizada en octubre 2 de 2013 (“Acuerdo en Avianca”, 2013). La medida de más de mil pilotos de suspender varios de los vuelos fue su reacción a la pérdida de poder adquisitivo de su salario por, en palabras de uno de los pilotos, "el sacrificio económico que venimos haciendo desde 2003 como contribución al proceso de fortalecimiento financiero de Avianca" (“Avianca cancela”, 2013, párr. 8). El impacto para los usuarios no se hizo esperar, esta huelga obligó a la cancelación de cientos de vuelos ("Acuerdo en Avianca", 2013) y, en un caso particular, los pasajeros incluso tuvieron que dormir en el interior del avión cuando los pilotos se negaron a volarlo ("Pilotos de Avianca", 2013).

Evolución de la organización en función de la evolución del contexto social: el narcotráfico y las narcoguerrillas

La evolución del narcotráfico y las narcoguerrillas también afectó la evolución de Avianca. A partir de la década de 1980, Colombia cobra mayor relevancia como país productor y exportador de cocaína en respuesta a la demanda en aumento de los consumidores en el mercado internacional, especialmente en los Estados Unidos (Arias, 2007, p. 344). Para 1988, Avianca había pagado multas de USD 14 millones por tráfico de estupefacientes y en 1987 se habían hallado 450 kilos de narcóticos en los aviones de la compañía, lo que induciría a Avianca a incrementar fuertemente sus medidas de detección de drogas (Funding Universe, 2001) con un consecuente aumento en los gastos. El atentado planeado por Pablo Escobar en noviembre de 1989 a un Boeing 727 que volaba de Bogotá a Cali fue otro duro golpe del narcotráfico (Miranda, 2012). Este golpe no solo disminuiría la confianza de los usuarios en Avianca, sino que exigiría que la compañía hiciera un seguimiento más a fondo de cada parte de los procesos que garantizaban la seguridad de los vuelos (Miranda, 2012). Finalmente, cabe comentar el secuestro en pleno vuelo de un Fokker 50 en la ruta Bucaramanga-Bogotá por parte de la para entonces ya narcoguerrilla ELN, el 12 de abril de 1999, lo que minaría aún más la confianza de los clientes de la compañía (Miranda, 2012). 
Evolución de la organización en función de la evolución del contexto económico internacional: los atentados del 11 de septiembre, la crisis del petróleo, la devaluación

Dos factores internacionales externos se conjugarían en contra de Avianca y afectarían su evolución en la década de 1990: el terrorismo y los altos precios del petróleo. Ya en 1991, la junta directiva justificaba las pérdidas acumuladas de USD 67,2 millones por el "efecto del terrorismo" que aumentaba las primas de seguros y los costos de seguridad y disminuía el número de pasajeros, así como por el aumento de los precios del combustible debido al conflicto en el Golfo Pérsico (Reyes, 2011, pp. 256-258).Los ataques terroristas del 11 de septiembre de 2001 y los altos precios del petróleo a principios de la década de 2000 continuarían con la tendencia perjudicial para la compañía ("Avianca: un vuelo turbulento", 2004). La devaluación, aunada a un periodo de recesión ("Lo que el viento se llevó", 2004; "Una historia de amor y dolor", 2004), estuvo igualmente rampante a finales de 2002 y afectó a Avianca, especialmente por tener que pagar algunos de sus costos - como los costos del combustible, los seguros y los leasings de los aviones - en dólares, mientras que gran parte de sus ingresos era en pesos ("Lo que el viento se llevó", 2004). ${ }^{5}$ Miranda Marín (2012) describe el entorno de la época así:

El 2002 fue un año de mucha crisis en la industria aérea, ya que se presentó una baja en la demanda de pasajeros tras los atentados terroristas en Estados Unidos del 11 de septiembre de 2001, la Guerra en el Medio Oriente, la recesión económica, y esto sumado a altos costos del petróleo y de los seguros generaba mayores costos a las aerolíneas, paralelamente en Colombia había mucha devaluación por la crisis que se presentó en Venezuela y Suramérica: y la situación político-social de ese momento en el país. (pp. 8-9).

\section{A MODO DE CONCLUSIÓN}

El principal factor del entorno que ha definido hasta el día de hoy la evolución de Avianca es el factor socio-económico. Avianca es, como organización del sector aeronáutico, prácticamente por definición, una empresa "procíclica", es decir, una empresa que en principio se espera que refleje en su evolución los ciclos socio-económicos. Por un lado, si el panorama socio-económico es positivo, Avianca tiene un buen prospecto, y viceversa, ya que los pasajeros tienden a viajar más y las empresas a contratar más envíos de carga cuando la economía está boyante. Por otro lado, el entorno estrictamente económico también influye directamente en la compañía, por ejemplo, a través de los precios del petróleo que conforman aproximadamente el 35\% de la estructura de costos de Avianca (Grupo Bancolombia, 2013). Del entorno económico, sin embargo, el aspecto más relevante hoy en día lo conforma la competencia directa que Avianca soporta: Avianca coevoluciona con 
su competencia, respondiendo a las estrategias de sus competidores e intentando aprovechar el crecimiento del sector, así, el número de pasajeros de Avianca en Colombia y en Perú ha aumentado en $224 \%$ y $340 \%$ en la última década, respectivamente (Grupo Bancolombia, 2013).Tras la fusión con TACA, Avianca se convirtió en una multinacional con tres hubs (Bogotá, Lima y El Salvador), líder en el mercado colombiano y centroamericano y en el segundo lugar en Perú (Grupo Bancolombia, 2013). Aunque Latinoamérica es el mercado de tráfico aéreo que crece más rápido en el mundo (Karp, 2013), la reciente incursión de Avianca como una fuerte multinacional aérea ha significado entrar a un entorno económico internacional en donde se lleva a cabo "una partida de ajedrez de altas apuestas" por ese mismo mercado (Airline Leader, 2012). Los jugadores son compañías como LATAM y Copa que también han resultado de recientes fusiones, mientras que localmente Avianca se enfrenta a la irrupción de la primera aerolínea de bajo costo colombiana VivaColombia (2014). LATAM es el resultado de la fusión desde 2012 entre la chilena LAN y la brasilera TAM (“Chile's Lan and Brazil's Tam", 2012), y aunque no han unificado sus marcas, cuentan con subsidiarias en Colombia (LAN Colombia, antes Aires) y Perú (LAN Perú) que compiten directa y enérgicamente con Avianca (Ch-aviation, 2014; LATAM Airlines Group S.A., 2014b). De hecho, LATAM cuenta hoy con 310 aviones de pasajeros y de carga y 55000 empleados (LATAM Airlines Group S.A., 2014a). Por su parte, la panameña Copa Airlines (2014) es dueña, desde 2005, de Copa Airlines Colombia, antes AeroRepública, una de las principales aerolíneas de Colombia; mientras que VivaColombia está compuesta por inversiones de la familia Ryan de Irlanda, los creadores de la famosa aerolínea de bajo costo Ryanair, y por inversiones del grupo de transporte terrestre mexicano IAMSA y del Grupo Bolívar de Colombia, entre otros (Yeo, 2012). Los movimientos de Efromovich, como tratar de incursionar en la aviación europea a través de Portugal (infructuosamente) o salir a la Bolsa de Nueva York (Crowe y Schaefer, 2013) son, en parte, respuesta a los fuertes retos de estos competidores de su entorno económico.

No obstante, a pesar de la influencia fundamental sobre Avianca del factor socio-económico del entorno, no debemos olvidar, sin embargo, los demás factores. Como hemos descrito a través de estas páginas, los otros factores tienen igualmente su relevancia y continuarán teniéndola. Quizás la moraleja más representativa de este estudio es que debemos analizar a Avianca como organización de manera holística, viendo su relación con el entorno como un todo, a la manera del pensamiento complejo. El entorno como macroestructura con sus diversas facetas afecta de diferentes maneras a Avianca, pero Avianca como microestructura también afecta recíprocamente al entorno. Por ejemplo, la apropiación tecnológica, incluyendo la de tecnologías administrativas, o las fusiones y maniobras financieras de los administradores y dueños de Avianca envían señales a los competidores que inducen a una suerte de "carrera armamentista" de estrategias cuando estos responden. Avianca continuará entonces siendo forjada por y siendo forjadora de su propio entorno, casi 
como un organismo vivo autopoiético que se autosustenta de los mismos procesos que hacen surgir la distinción entre su interior (organización) y su exterior (entorno).

\section{NOTAS}

1 Cabe anotar que al momento de la fusión ACES era "propiedad en 72,6 por ciento de la Federación Nacional de Cafeteros" (Reyes, 2011, pp. 326-328).

2 Los grupos económicos de Julio Mario Santo Domingo y Carlos Ardila Lülle han sido muy bien descritos en "Seguimiento a la dinámica competitiva de dos grupos económicos colombianos", por C. Rodríguez y E. J. Duque, 2007, Revista Innovar, 17(29), 137-154, y son bien conocidos para los colombianos, por lo que no ahondamos en introducirlos.

3 Los "poderes de ventanilla", una práctica común en el país, consistían en que accionistas insignificantes le daban un poder a accionistas mayores para que los representaran, véase: "El arte perdido de investigar", por J. M. Álvarez, El Malpensante, (136). Recuperado de http://www. elmalpensante.com/articulo/2700/el_arte_perdido_de_investigar/

$4 \quad$ La mitad de ese dinero sería girada en efectivo y la otra mitad asumida por Valores Bavaria, el holding de Santo Domingo, como un compromiso sobre el pasivo laboral ("Lo que el viento se llevó”, 2004).

5 De hecho, la tasa representativa del mercado pasaría de COP 2291 al iniciar el año para terminar en COP 2 865, véase Tasa de cambio representativa del mercado (TRM), por Banco de la República, 2014, recuperado de http://obiee.banrep.gov.co/analytics/saw.dll?Go\&NQUser $=$ publico $\& N Q P a s s w o r d=$ publico $\&$ Path $=/$ shared/Consulta $\% 20$ Series $\% 20$ Estadisticas $\% 20$ desde $\% 20$ Excel $/ 1 . \% 20$ Tasa $\% 20 \mathrm{de} \% 20$ Cambio\%20Peso\%20Colombiano/1.1\%20TRM\%20 -\%20Disponible\%20desde\%20el\%2027\%20de\%20noviembre\%20de\%201991/1.1.1\%20 Serie $\% 20$ historica\&Options $=$ rdf/

\section{REFERENCIAS}

Acuerdo en Avianca pone fin a operación cero trabajo suplementario. (2 de octubre de 2013). Caracol. Recuperado de http://www.caracol.com.co/noticias/actualidad/acuerdo-en-avianca-pone-fin-a-operacion-cero-trabajo-suplementario/20131002/nota/1987262.aspx/

Airline Leader. (2012). Global alliances in Latin America: a high stakes chess match. Recuperado de http://www.airlineleader.com/this-months-highlights/global-alliances-in-latin-america-a-highstakes-chess-match/

Arenas, C. y Úsuga, G. (2013). Aerolíneas integradas en Avianca Holdings S.A. presentan su marca comercial única: Avianca [Boletín de prensa]. Colombia: Avianca.

Arias, R. (2007). Del frente nacional a nuestros días, Historia de Colombia: todo lo que hay que saber. Colombia: Taurus. 
Avenier, M. J. (1989). 'Méthodes de terrain' et recherche en management stratégique. Economies et Sociétés, 14, 199-218.

Aviación y Turismo. (2012). La historia de Avianca, la segunda aerolínea más antigua del mundo. Recuperado de http://aviacionyturismo.com/2012/12/05/avianca-93-anos/

Avianca. (2013). Perfil corporativo. Recuperado de http://www.avianca.com/es-co/nuestra-compania/ informacion-institucional/perfil-corporativo.aspx/

Avianca cancela 160 vuelos por huelga de pilotos. (14 de septiembre de 2013). 24 Horas. Recuperado de http://www.24horas.cl/internacional/avianca-cancela-160-vuelos-por-huelga-de-pilotos-843444/

Avianca Cargo. (2013). Company History. Recuperado de http://www.aviancacargo.com/eng/com/history.aspx\#avianca/

Avianca coloca bonos por $\$ 500.000$ millones, con el fin de establecer una plataforma sólida para invertir. (25 de agosto de 2009). Portafolio. Recuperado de http://www.portafolio.co/detalle_archivo/CMS-5939809/

Avianca Holdings S.A. (2013). [Corporate presentation (Vol. 2014)]. Colombia: Avianca Holdings.

Avianca y Sky Airline abren rutas internas por acuerdo de código compartido. (29 de mayo de 2012). El Economista. Recuperado de http://www.eleconomista.net/2012/05/29/empresas/133948-avianca-y-sky-airline-abren-rutas-internas-por-acuerdo-de-codigo-compartido-html/

Avianca, de la quiebra al corazón de Wall Street. (6 de noviembre de 2013). Portafolio. Recuperado de http://www.portafolio.co/negocios/avianca-la-quiebra-al-corazon-wall-street/

Avianca: un vuelo turbulento. (17 de septiembre de 2004). Dinero. Recuperado de http://m.dinero.com/ edicion-impresa/especial-comercial/articulo/avianca-vuelo-turbulento/24755/

Ávila, R. (2014). Forbes. Recuperado de http://www.forbes.com/profile/roberto-avila/

Barab, R. (2005). The Avianca miracle. Trust the Leaders, 12, 11-20.

Bogotá, puerta de entrada al continente. (25 de septiembre de 2000). El Tiempo. Recuperado de http://www.eltiempo.com/archivo/documento/MAM-1209926/

Bourdieu, P., Passeron, J. C. y Chamboredon, J. C. (1975). El oficio de sociólogo: presupuestos epistemológicos. México: Siglo XXI Editores.

Calia, M. (2013). Avianca Holdings files for IPO of up to $\$ 100$ million in ADSs. The Wall Street Journal. Recuperado de http://online.wsj.com/article/BT-CO-20130919-710775.html/

Ch-aviation. (2014). LAN Colombia. Recuperado de http://www.ch-aviation.com/portal/airline/LAB/

Chile's Lan and Brazil's Tam merge to create huge airline. (22 de junio 2de 012). British Broadcasting Corporation News. Recuperado de http://www.bbc.com/news/world-latin-america-18560343/ 
Copa Airlines. (2014). Aero República brand name change. Recuperado de https://www.copaair.com/ sites/cc/en/acerca-de-copa-airlines/pages/faq-cambio-de-marca.aspx/

Crowe, D. y Schaefer, S. (2013). Colombia's Avianca to announce New York stock sale. The Wall Street Journal. Recuperado de http://blogs.wsj.com/moneybeat/2013/09/09/colombias-avianca-toannounce-new-york-stock-sale/

Dias, K. (2013). Ocean Air (1998-2010). Mundo das Marcas. Recuperado de http://mundodasmarcas. blogspot.com/2006/10/ocean-air-voc-faz-gente-crescer.html/

El milagro de Avianca. (24 de febrero de 2007). Semana. Recuperado de http://www.semana.com/economia/articulo/el-milagro-avianca/83650-3/

Funding Universe. (2001). Avianca Aerovías Nacionales de Colombia SA History. Recuperado de http://www.fundinguniverse.com/company-histories/avianca-aerov-iacute-nacionales-de-colombia-sa-history/

George, S. (1999). A short history of neo-liberalism. Recuperado de http://www.globalexchange.org/ resources/econ101/neoliberalismhist/

Grupo Bancolombia. (2013). Avianca Holdings. Investigaciones renta variable Colombia. Recuperado de http://investigaciones.bancolombia.com/inveconomicas/(lnoe0p45d2edym45pdjpk0uy)/ sid/30210/20130101609445664.pdf/

Hoskisson, R. E., Hitt, M. A. y Ireland, R. D. (2004). Competing for advantage. Estados Unidos: South-Western/Thomson Learning.

Johnson, S., La Porta, R., Lopez-de-Silanes, F. y Shleifer, A. (2000). Tunneling. The American Economic Review, 90(2), 22-27.

Karp, A. (2013). Avianca's Aspirations. Air Transport World, 50(12), 20-24.

Kelly, L. (2008). Neoliberalism in Latin America. Recuperado de http://citizenspress.org/editorials/ neoliberalism-in-latin-america/

KienyKe. (2011). Pelea de pesos pesados. Recuperado de http://www.kienyke.com/historias/pelea-de-pesos-pesados/

Kliksberg, B. (1975). El pensamiento organizativo: del Taylorismo a la teoría de la organización. La administración científica en discusión. Argentina: Paidós.

La venta de Avianca. (21 de agosto de 2013). Dinero. Recuperado de http://www.dinero.com/edicion-impresa/caratula/articulo/la-venta-avianca/182451/

LATAM Airlines Group S.A. (2014a). About us. Recuperado de http://www.latamairlinesgroup.net/ phoenix $. z h t m l ? c=81136 \& p=$ irol-homeProfile $2 /$

LATAM Airlines Group S.A. (2014b). Descripción y Estrategia del Negocio. Recuperado de http:// www.lan.com/es_ar/investor_relations/compania/estrategia_descripcion.html/ 
Le Moigne, J. L. (1997). La 'incoherencia epistemológica' de las ciencias de gestión. Cuadernos de Economia, 16(26), 163-185.

León, K. (2008). La Compañía Colombiana de Navegación Aérea, 1919-1921. Una aventura empresarial pionera en Suramérica. Lecturas de Economía, 68, 197-215.

León, K. (2011). Historia de la aviación en Colombia, 1911-1950. Credencial Historia, 264. Recuperado de http://www.banrepcultural.org/blaavirtual/revistas/credencial/diciembre2011/aviacion/

Lima, E. P. (1998). Reshaping Avianca. Air Transport World, 35(5), 81-83.

Lo que el viento se llevó. (21 de marzo de 2004). Semana. Recuperado de http://www.semana.com/ portada/articulo/lo-viento-llevo/64305-3/

Los detalles del negocio Avianca-Taca. (8 de octubre de 2009). Semana. Recuperado de http://www. semana.com/economia/negocios/articulo/los-detalles-del-negocio-avianca-taca/108445-3/

Maturana, H. y Varela, F. J. (1994). De máquinas y seres vivos. Autopoiesis: la organización de lo vivo. Chile: Editorial Universitaria.

Mejía, A. (2013). German Efromovich, quite a prominent and self-made businessman in Latin Ameri$c a$. Recuperado de http://abelmejiajr.com/german-efromovich-quite-a-prominent-and-self-made-businessman-in-latin-america/

Mendoza, A. F. (1994). Setenta y cinco años de progreso. Lámpara, 32(124), 15-24.

Miranda, P. E. (2012). Decisiones administrativas estratégicas de Avianca: pasado, presente y futuro de una empresa competitiva. Recuperado de http://repository.ean.edu.co/bitstream/10882/3261/7/ MirandaPaola2012.pdf/

Muñoz, R. (2011). Formar en administración. Por una nueva fundamentación filosófica. Colombia: Siglo del Hombre Editores y Fondo Editorial EAFIT.

Parra, B. (1995). Avianca hace pérdidas volando. Revista Innovar, 6, 7-33.

Pilotos de Avianca abandonan avión y dejan a pasajeros dentro de éste. (13 de septiembre de 2013). El Universal. Recuperado de http://www.eluniversal.com.co/cartagena/pilotos-de-avianca-abandonan-avion-y-dejan-pasajeros-dentro-de-este-134576/

Prigogine, I. (1997). ¿Tan sólo una ilusión? Una exploración del caos al orden. España: Tusquets.

Reyes, G. (2011). Don Julio Mario. Colombia: Random House Mondadori.

Rodríguez, C. y Duque, E. J. (2007). Seguimiento a la dinámica competitiva de dos grupos económicos colombianos. Revista Innovar, 17(29), 137-154.

Saenz, M. (2010). Nace SCADTA. Recuperado de http://www.colombialink.com/01_INDEX/index_ historia/07_otros_hechos_historicos/0150_nace_scadta.html/ 
Santamaría, R. (2009). Avianca y Taca retan a las grandes ligas del negocio en el continente. El Tiempo. Recuperado de http://www.eltiempo.com/archivo/documento/MAM-3660107/

Santos, E. (2009). Colombia día a día. Colombia: Editorial Planeta.

Star Alliance. (2014). Beneficios de la alianza. Recuperado de http://www.staralliance.com/es/benefits/

U.S. Department of Justice \& the Federal Trade Commission. (2010). Horizontal Merger Guidelines. Recuperado de https://www.ftc.gov/sites/default/files/attachments/merger-review/100819hmg. pdf/

Una de las flotas más jóvenes y modernas del mundo. (24 de septiembre de 1992). El Tiempo. Recuperado de http://www.eltiempo.com/archivo/documento/MAM-208778/

Una historia de amor y dolor. (21 de marzo de 2004). Semana. Recuperado de http://www.semana.com/ portada/articulo/una-historia-amor-dolor/64306-3/

Urrutia, M. (1982). El desarrollo del movimiento sindical y la situación de la clase obrera. En S. Mutis (Ed.), Manual de historia de Colombia (Vol. 3). Bogotá: Procultura.

VivaColombia. (2014). Nuestra aerolínea. Recuperado de http://www.vivacolombia.co/co/nuestraaerolinea.htm/

Yeo, G. L. (2012). VivaColombia to launch operations on 25 May. Flightglobal. Recuperado de http:// www.flightglobal.com/news/articles/vivacolombia-to-launch-operations-on-25-may-372141/ 